\title{
Induced Germinal Center B Cell Culture System
}

Kei Haniuda* and Daisuke Kitamura

Division of Molecular Biology, Research Institute for Biomedical Sciences (RIBS), Tokyo University of Science, Noda, Chiba, Japan

*For correspondence: haniuda@rs.tus.ac.jp

[Abstract] The germinal center (GC) is the site where B cells undergo clonal expansion, affinity-based selection, and differentiation into memory $B$ cells or plasma cells. It has been difficult to elucidate regulatory mechanisms for the dynamic $\mathrm{GC} B$ cell maturation and differentiation, partly because experimental manipulation of GC B cells in vivo has been limited and no in vitro system has been available that resembles $B$ cell reaction in GC. Here we describe the protocol for a culture system named "induced GC B (iGB) culture system" which can induce massive expansion of B cells that exhibit $G C B$ cell-like phenotype, and thus it mimics the $G C$ reaction. This protocol can be useful to elucidate the molecular mechanisms of $\mathrm{GC} B$ cell differentiation.

Keywords: iGB cell, 40LB cell, CD40L, BAFF, Germinal center, Memory B cell, B cell culture

[Background] In the field of T cell immunology, in vitro culture systems that allow differentiation of naive $T$ cells toward specific effector $T$ cell subsets have been widely used to study molecular mechanisms for the T-cell differentiation. However, there has been no practical culture system to effectively induce expansion of $B$ cells with high viability and differentiation towards $G C B$ cells. To study the GC B cell biology in vitro, we have developed a novel B-cell culture system that mimics GC B-cell reaction (Nojima et al., 2011). For this system, we generated a feeder cell line named 40LB, a Balb/c 3T3 cell line expressing exogenous CD40-ligand (CD4OL) and B-cell activating factor (BAFF) that together promote $B$ cell proliferation and survival. When naive $B$ cells are cultured with IL- 4 for the first 4 days and then with IL-21 for the second 4 days on the feeder cells, B cells proliferate exponentially up to 10,000 fold, efficiently undergo isotype switching to $\lg G 1$ and $\lg E$, the Th2 related isotypes, and express GC B-cell markers such as GL7 and Fas. Thus, we termed the B cells propagated in this system in-vitro-induced GC B (iGB) cells, and this system the iGB cell culture system. Compared to simply stimulating B cells with anti-CD40 antibody and BAFF with IL-4, which can induce only a 20-fold expansion of B cells in 6 days and less efficient isotype switching, iGB cell culture system is very useful. The iGB cell culture system have been widely used to study B cell biology, such as GC B cell expansion and differentiation, signaling from various receptors, immunoglobulin gene class-switch recombination, and so on (Fukao et al., 2014; Haniuda et al., 2016). The iGB cells not only phenotypically resemble genuine $G C B$ cells but they functionally mimic some aspects of $G C B$ cells: the iGB cells after the primary culture with IL-4 differentiate in vivo into memory-like B cells when transferred into mice, whereas those after the secondary culture with IL-21 differentiate in vivo into plasma cells that are relatively long-lived (Nojima et al., 2011; Moutai et al., 2014). Hence the iGB cell 
culture system is also applicable for the studies of molecular mechanisms for their differentiation into memory B cells or long-lived plasma cells, and their responses (Takatsuka et al., 2018). Here, we describe a detailed protocol for the iGB cell culture system.

\section{Materials and Reagents}

1. $50 \mathrm{ml}$ tube (Thermo, catalog number: 339652 )

2. $15 \mathrm{ml}$ tube (Thermo, catalog number: 339650 )

3. $5 \mathrm{ml}$ round-bottom tube (Falcon, catalog number: 352054)

4. $10 \mathrm{~cm}$ dish (Falcon, catalog number: 353003 )

5. 6-well plate (Costar, catalog number: 3516)

6. 12-well plate (Costar, catalog number: 3513 )

7. $26 \mathrm{G}$ needle (Terumo, catalog number: NN-2613S)

8. $10 \mathrm{ml}$ syringe (Terumo, catalog number: SS-10SZ)

9. Cryovial (Thermo, catalog number: 375418 )

10. Frosted glass slides (Matsunami, catalog number: S2226)

11. MACS LS Columns (Miltenyi Biotec, catalog number: 130-042-401)

12. $100 \mu \mathrm{m}$ mesh (TGK, catalog number: $\mathrm{N}-\mathrm{No} .200 \mathrm{HD}$ )

13. $40 \mu \mathrm{m}$ mesh (TGK, catalog number: $\mathrm{N}-\mathrm{No} .355 \mathrm{~T}$ )

14. 40LB cells: BALB/c3T3 cells (provided by RIKEN BRC) stably expressing mouse CD40L and mouse BAFF (Nojima et al., 2011)

15. D-MEM (high glucose, WAKO, catalog number: 044-29765)

16. Fetal bovine serum (FBS, see Notes)

17. Trypsin-EDTA (WAKO, catalog number: 204-16935)

18. Penicillin-streptomycin (Gibco, catalog number: 15140-122)

19. RPMI-1640 (WAKO, catalog number: 189-02025)

20. HEPES (Dojindo, catalog number: 346-08235)

21. 2-mercaptoethanol (2-ME, Gibco, catalog number: 21985-023)

22. $\mathrm{NaCl}$ (WAKO, catalog number: 195-01663)

23. $\mathrm{KCl}$ (WAKO, catalog number: 163-03545)

24. $\mathrm{Na}_{2} \mathrm{HPO}_{4}$ (WAKO, catalog number: 196-02835)

25. $\mathrm{KH}_{2} \mathrm{PO}_{4}$ (WAKO, catalog number: 169-04245)

26. EDTA (Dojindo, catalog number: 345-01865)

27. Biotinylated anti-CD43 (BD Pharmingen, clone: S7, catalog number: 553269)

28. Biotinylated anti-Ter119 (Biolegend, clone: TER-119, catalog number: 116204)

29. Biotinylated anti-CD4 (Biolegend, clone: GK1.5, catalog number: 100404)

30. Biotinylated anti-CD8 (Biolegend, clone: 53-6.7, catalog number: 100704)

31. Biotinylated anti-CD49b (Biolegend, clone: DX5, catalog number: 108904)

32. Biotinylated anti-H-2Kd (Biolegend, clone: SF1-1.1, catalog number: 116604) 
33. Biotinylated anti-CD138 (Biolegend, clone: 281-2, catalog number: 142512)

34. Streptavidin Particles Plus-DM (BD, IMag, catalog number: 557812)

35. Recombinant mouse IL-4 (PeproTech, catalog number: 214-14)

36. Recombinant mouse IL-21 (PeproTech, catalog number: 210-21)

37. ЗТЗ medium (see Recipes)

38. B cell medium (BCM) (see Recipes)

39. Phosphate-buffered saline (PBS) (see Recipes)

40. MACS buffer (see Recipes)

41. Antibody cocktail for B cell isolation (for one spleen) (see Recipes)

42. Antibody cocktail for feeder cell depletion (for cells) (see Recipes)

\section{Equipment}

1. Pipettes

2. Autoclave

3. $37^{\circ} \mathrm{C}$ water bath

4. $\mathrm{CO}_{2}$ incubator (Panasonic, catalog number: MCO-170AIC-PJ)

5. Laminar flow hood (SANYO, Bio clean bench)

6. Mr. Frosty (Thermo, catalog number: 5100-0001)

7. $-80^{\circ} \mathrm{C}$ freezer

8. Liquid nitrogen storage tank

9. Cell separation Magnet (BD IMag, catalog number: 552311)

10. Centrifuge (Kubota, 4000, 5911, 6200)

11. MACS MultiStand (Miltenyi Biotec, catalog number: 130-042-303)

12. MidiMACS Separator (Miltenyi Biotec, catalog number: 130-042-302)

\section{Procedure}

A schematic overview of the experimental procedure is shown in Figure 1. 


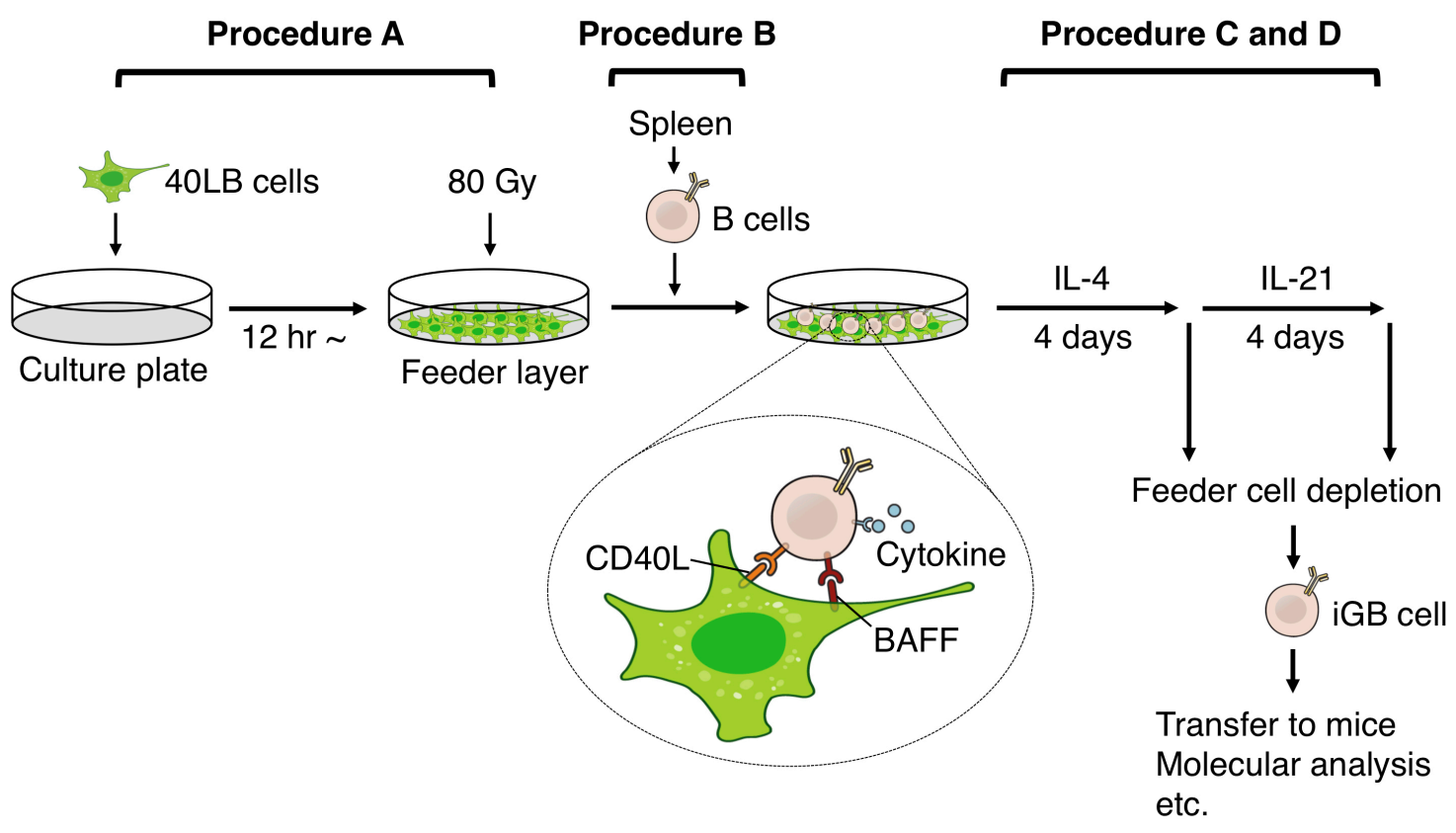

Figure 1. A schematic illustration of the procedure for iGB cell culture system

A. Propagation of $40 \mathrm{LB}$ cells and preparation of feeder layer of $40 \mathrm{LB}$ cells

4OLB feeder cells are typically cultured and maintained with $10 \mathrm{ml}$ of $3 T 3$ medium in a $10 \mathrm{~cm}$ dish at $37^{\circ} \mathrm{C}, 5 \% \mathrm{CO}_{2}$. Passage the 40LB cells every 3 days with 6 -fold dilutions and keep in culture up to one month, as described below. After one month or so, restart the culture from a frozen stock. The following protocol is for the culture using $10 \mathrm{~cm}$ dishes. Change the volume of solutions in proportion to the bottom area of the plate (well) to use, as shown by examples in Table 1.

1. Thaw a frozen $1 \mathrm{ml} 40 \mathrm{LB}$ cell stock and dilute the content with $12 \mathrm{ml}$ of $3 T 3$ medium (see Recipes).

2. Centrifuge cells at $270 \times g$ for $5 \mathrm{~min}$ at $4{ }^{\circ} \mathrm{C}$.

3. Discard the supernatant and resuspend the cells in $10 \mathrm{ml}$ of $3 Т 3$ medium by pipetting, and seed all cells into a $10 \mathrm{~cm}$ culture dish.

4. Culture cells at $37{ }^{\circ} \mathrm{C}, 5 \% \mathrm{CO}_{2}$ for $1-2$ days until they reach $70 \%-80 \%$ confluence.

5. Remove the medium from the cell culture dish, and rinse it with $2 \mathrm{ml}$ of PBS (see Recipes).

6. Discard the PBS, add $1 \mathrm{ml}$ of Trypsin-EDTA and leave the dish at room temperature until cells get dispersed (it takes about 1-3 min).

7. Add $3 \mathrm{ml}$ of ЗТЗ medium and gently pipette up and down to completely detach the cells.

8. Transfer the cell suspension to a tube and centrifuge at $270 \times \mathrm{g}$ for $5 \mathrm{~min}$ at $4{ }^{\circ} \mathrm{C}$.

9. Discard the supernatant and resuspend the cells in the desired volume of 3 T3 medium.

10. For passage, dilute cell suspension 6-fold from Step A9, seed cells into $10 \mathrm{~cm}$ culture dishes and culture cells at $37^{\circ} \mathrm{C}, 5 \% \mathrm{CO}_{2}$ for 3 days.

11. For irradiation, seed an appropriate number of $40 \mathrm{LB}$ cells from Step $A 9$ to the desired plate (see Table 1), and allow cells at least $12 \mathrm{~h}$ to attach the plate. Alternatively, irradiate the 
harvested 4OLB cells in a tube, then seed them onto plates, and culture them for at least $12 \mathrm{~h}$ until the 40LB cells attach to the plates and completely spread out.

12. Irradiate the cells with $80 \mathrm{~Gy}$ of $\mathrm{y}$-ray to stop proliferation.

13. For cell stock, resuspend the cell pellet from Step A9 in ice-cold 20\% FBS and 10\% DMSO ( 2 $x 10^{6}$ cells per $\mathrm{ml}$ ), add $1 \mathrm{ml}$ of cell suspension to each cryovial, place the vials in a Mr. Frosty, then place the cells in a $-80^{\circ} \mathrm{C}$ deep freezer for $24 \mathrm{~h}$. After $24 \mathrm{~h}$, transfer the vials to a liquid nitrogen storage tank.

Table 1. Plate type, cell number to seed and volume of solutions

\begin{tabular}{|l|l|l|l|}
\hline Plate type & $10 \mathrm{~cm}$ & 6 -well & 12 -well \\
\hline No. of 4OLB cells to seed $\left(\times 10^{4}\right)$ & 300 & 50 & 20 \\
\hline Vol. of PBS to rinse a dish or a well $(\mathrm{ml})$ & 2 & 0.5 & 0.25 \\
Vol. of Trypsin-EDTA to harvest cells $(\mathrm{ml})$ & 1 & 0.5 & 0.25 \\
Vol. of 3T3 medium to inactivate trypsin $(\mathrm{ml})$ & 3 & 1 & 0.5 \\
\hline No. of B cells to seed $\left(\times 10^{4}\right)$ & 50 & 5 & 2 \\
\hline Vol. of BCM to seed $(\mathrm{ml})$ & 40 & 8 & 4 \\
\hline
\end{tabular}

B. Isolation and purification of B cells from mouse spleen for the iGB cell culture Keep cells on ice or $4{ }^{\circ} \mathrm{C}$, and use pre-chilled solutions. The following is the protocol for one spleen.

1. Take a spleen from a C57BL/6 mouse and put the spleen in a $10 \mathrm{~cm}$ dish.

2. Inject $10 \mathrm{ml}$ of MACS buffer (see Recipes) inside the spleen using a $26 \mathrm{G}$ needle and $10 \mathrm{ml}$ syringe, in order to extract splenocytes, and then gently disrupt the remaining spleen capsular using a pair of frosted glass slides.

3. Transfer the cell suspension with a pipette to a tube through a $100 \mu \mathrm{m}$ mesh.

4. Centrifuge at $370 \times g$ for 6 min.

5. Discard the supernatants, resuspend the cells with $10 \mathrm{ml}$ of MACS buffer and count the cell number.

6. Discard the supernatant, add $100 \mu \mathrm{l}$ of antibody cocktail for B cell isolation (see Recipes) per $10^{8}$ cells and gently pipette up and down to suspend the cells completely.

7. Incubate for $20 \mathrm{~min}$ on ice.

8. Wash the cells twice by adding $10 \mathrm{ml}$ of MACS buffer with centrifugation ( $370 \times g$ for $6 \mathrm{~min}$ ) at each step.

9. Discard the supernatants, add $50 \mu$ of Streptavidin Particles Plus-DM per $10^{8}$ cells and gently pipette up and down to suspend the cells completely.

10. Incubate the cells for $20 \mathrm{~min}$ on ice.

11. Place two $5 \mathrm{ml}$ round-bottom tubes onto the IMag cell separation Magnet.

12. Resuspend cells with $2 \mathrm{ml}$ of MACS buffer and transfer into the first tube on the magnet. 
13. Wait for 5 min until the labeled cells attach to the wall of the tube beside the magnet.

14. Collect unbound cells from the first tube and transfer it to the second tube.

15. Detach the first tube and resuspend the attached cells in the first tube with a new $2 \mathrm{ml}$ of MACS buffer, and then place the tube back onto the magnet and leave it for $5 \mathrm{~min}$.

16. Collect unbound cells from the second tube and transfer it to the collection tube.

17. Repeat Steps B13-B15 once more.

18. Collect unbound cells from the first tube, transfer it to the second tube and leave it for $5 \mathrm{~min}$.

19. Collect unbound cells from the second tube and transfer it to the collection tube.

20. Centrifuge the whole collected cells at $370 \times g$ for 6 min.

21. Place an LS column onto a MidiMACS Separator attached to MACS MultiStand, and place $40 \mu \mathrm{m}$ mesh on the top of the LS column.

22. Rinse the column with $2 \mathrm{ml}$ of MACS buffer.

23. Discard the supernatants from Step B19 and resuspend the cells with $1 \mathrm{ml}$ of MACS buffer.

24. Apply the cell suspension onto the LS column through the $40 \mu \mathrm{m}$ mesh and allow all the suspension to pass through the column.

25. Wash the column 3 times with $1 \mathrm{ml}$ of MACS buffer each.

26. Wash the column once with $3 \mathrm{ml}$ of MACS buffer.

27. Collect all the effluent and centrifuge at $370 \times g$ for 6 min.

28. Discard the supernatants, resuspend the cells with $10 \mathrm{ml}$ of $\mathrm{B}$ cell medium (BCM, see Recipes) and count the cell number.

Note: The expected $B$ cell number from one spleen is $2 \times 10^{7}-5 \times 10^{7}$ cells.

29. Check the purity of isolated $B$ cells using flow cytometry. Use fluorochrome-conjugated antibodies against B cell markers such as CD19 and B220. The purity of B cells is usually more than $97 \%$.

Note: Alternatively, positively sorted B cells using MACS or FACS can be used for the culture. B cells from peripheral blood or other lymphoid organs such as lymph nodes can also be used.

C. iGB cell culture

Use pre-warmed buffer and medium. The following protocol is for the culture using a $10 \mathrm{~cm}$ dish. Note: After the B cells start to proliferate and become ' $i G B$ cells', the iGB cells should be treated at room temperature during all procedures such as centrifugation, antibody staining, iMag, MACS or flow cytometry, etc. iGB cells tend to die on ice.

1. Remove culture medium of irradiated feeder cells from the $10 \mathrm{~cm}$ dish and add $35 \mathrm{ml}$ of BCM supplemented with IL-4 (final concentration is $1 \mathrm{ng} / \mathrm{ml}$ ).

2. Add $5 \mathrm{ml}$ of BCM containing an appropriate number of the isolated $B$ cells (see Table 1 ) and culture at $37^{\circ} \mathrm{C}, 5 \% \mathrm{CO}_{2}$ for 4 days (Figure 2). 

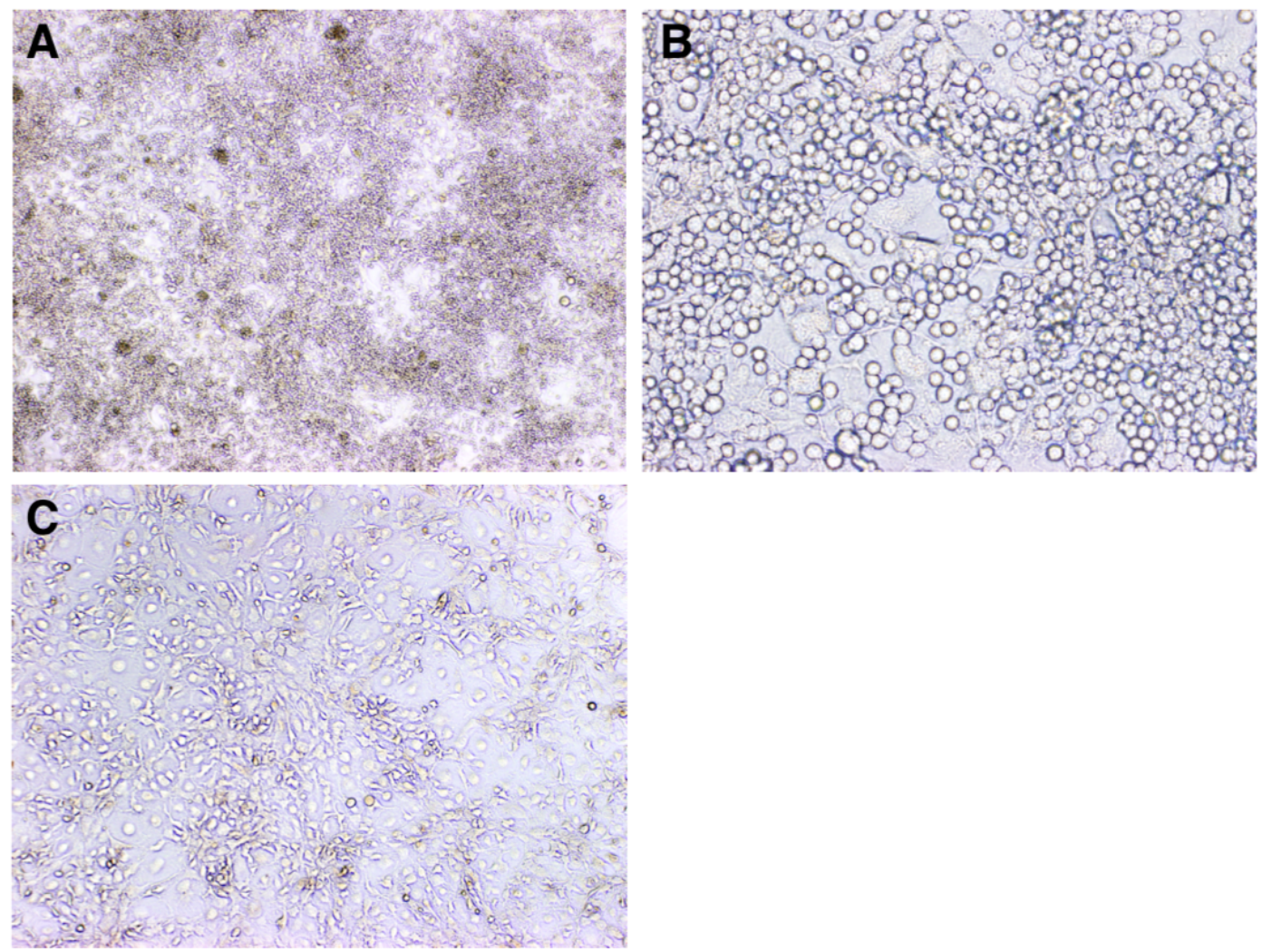

Figure 2. Bright-field microscopy of the iGB cells and a 40LB layer. A and $B$. iGB cells on a feeder layer after culturing with IL-4 for 4 days. (A) 4x magnification, (B) 20x magnification. C. 40LB feeder layer after $80 \mathrm{~Gy}$ irradiation at $4 \mathrm{x}$ magnification.

3. To harvest cells, carefully remove medium from the surface down to the level about $0.5 \mathrm{~cm}$ above the bottom and transfer the remaining medium to a collection tube (the volume of remaining medium is about $10 \mathrm{ml}$ ).

4. Add $4 \mathrm{ml}$ of MACS buffer and leave dish at room temperature until cells begin to get dispersed (it takes about 3-5 min).

5. Gently shake the dish to detach the cells and collect them to the tube.

6. Rinse the plate with $5 \mathrm{ml}$ of MACS buffer and collect the medium into the tube. Repeat once more.

7. Centrifuge all the collected cells at $370 \times g$ for $5 \mathrm{~min}$ at room temperature.

8. Discard the supernatants and disrupt the cell pellet by gentle shaking. Resuspend the cell pellet with $10 \mathrm{ml}$ of $B$ cell medium and count the cell number. iGB cells are distinguishable as the cells smaller than the $40 \mathrm{LB}$ cells.

Note: The expected iGB cell number from a $10 \mathrm{~cm}$ dish is $2 \times 10^{7}-4 \times 10^{7}$, and the viability of iGB cells exceeds $90 \%$.

9. To culture the cells sequentially, seed appropriate number of the iGB cells onto a new irradiated feeder layer and culture them as described in Step C1 with an appropriate cytokine.

Note: Primary cultured iGB cells can be re-expanded on the new feeder layer with $10 \mathrm{ng} / \mathrm{ml}$ 
IL-21 (or IL-4 which will promote further switching to IgE), as described in the original article (Nojima et al., 2011). For this, put the whole harvested cells including the feeder cells onto the new feeder layer, adjusting the number of iGB cells as desired. For example, primary iGB cells on Day 4 can be seeded, to culture with IL-21, at $5 \times 10^{5}$ (for 3 more days) or $5 \times 10^{4}$ (for 4 more days) per $10 \mathrm{~cm}$ dish. In the secondary culture with $\mathrm{IL}-21$, the growth rate of iGB cells is difficult to predict, thus change the medium when it begins to turn yellowish. In our experience, the expected expansion factor of iGB cell during the secondary culture is 100-300 fold (in 4 days), and the viability of iGB cells always exceeds $70 \%$. The secondary culture can be continued for at least 6 days without feeder renewal.

D. Feeder cell depletion

It is desirable to remove feeder cells from harvested cells of the iGB cell culture when they are transferred into mice or analyzed at a molecular level. This depletion protocol is for cells from one $10 \mathrm{~cm}$ dish. Use pre-warmed buffer and medium.

1. Harvest cells as in Steps C3-C7.

2. Discard the supernatants and disrupt the cell pellet with gentle shaking. Add $260 \mu \mathrm{l}$ of an antibody cocktail for feeder cell depletion (see Recipes) and gently pipette up and down to suspend the cells completely. For cells from 1 well of a 6 -well or 12 -well plate, use 1/6 or 1/12 volume, respectively, of diluted antibody with the same concentration.

3. Incubate for $20 \mathrm{~min}$ at room temperature.

4. Wash the cells twice by adding $10 \mathrm{ml}$ of MACS buffer with centrifugation (370 $\mathrm{xg}$ for $5 \mathrm{~min}$ at room temperature) at each step.

5. Discard the supernatant and disrupt the cell pellet with gentle shaking. Add $50 \mu \mathrm{l}$ of Streptavidin Particles Plus-DM and $100 \mu \mathrm{l}$ of MACS buffer, and then gently pipette up and down to suspend the cells completely.

6. Incubate for $20 \mathrm{~min}$ at room temperature.

7. Apply to iMag and MACS procedure as described in Steps B10-B24.

8. Collect all the effluent and centrifuge at $370 \times \mathrm{g}$ for $5 \mathrm{~min}$ at room temperature.

9. Resuspend the collected cells in $10 \mathrm{ml}$ of an appropriate medium or buffer and count the cell number.

\section{Notes}

An FBS lot check is required, as lot-specific differences in FBS influence the cell growth, class switching and the generation of the iGB cells. Indeed, only $\sim 30 \%$ of the lots we tested worked well. When we select the FBS lot for iGB cell culture, we usually use the following parameters: 1) Cell expansion factor during the primary culture with IL-4 (more than 60-fold in $96 \mathrm{~h}$ ) and the secondary culture with IL-21 (more than 100-fold in $96 \mathrm{~h}$ ). 2) FACS profiles after the primary and the secondary culture: efficient class switching to $\lg G 1$ and $\lg E$ (but no more than $50 \% \lg \mathrm{E}^{+}$cells) and 
homogeneous expression of GL7 and Fas, and minimal differentiation to CD138 ${ }^{+}$cells after the primary culture. Most of the FBS lots can support the expansion and survival of $40 \mathrm{LB}$ cells.

\section{$\underline{\text { Recipes }}$}

Note: When preparing the following solutions, mix all of components in a sterile hood.

1. 3 T 3 medium

D-MEM supplemented with $10 \%$ heat-inactivated fetal bovine serum (FBS)

$100 \mathrm{U} / \mathrm{ml}$ penicillin

$100 \mu \mathrm{g} / \mathrm{ml}$ streptomycin

Store at $4{ }^{\circ} \mathrm{C}$, Shelf life: 2 months from the date of manufacture

Note: FBS can be heat-inactivated by incubation at $56{ }^{\circ} \mathrm{C}$ for $30 \mathrm{~min}$.

2. B cell medium (BCM)

RPMI-1640 supplemented with $10 \%$ heat-inactivated FBS

$10 \mathrm{mM}$ HEPES-NaOH $\mathrm{pH} 7.5$

$5.5 \times 10^{-5} \mathrm{M} 2-\mathrm{ME}$

$100 \mathrm{U} / \mathrm{ml}$ penicillin

$100 \mu \mathrm{g} / \mathrm{ml}$ streptomycin

Store at $4{ }^{\circ} \mathrm{C}$, Shelf life: 2 months from the date of manufacture

3. Phosphate-buffered saline (PBS)

a. Stock (20x): dissolve $160 \mathrm{~g} \mathrm{NaCl}, 4 \mathrm{~g} \mathrm{KCl}, 23 \mathrm{~g} \mathrm{Na}_{2} \mathrm{HPO}_{4}$ and $4 \mathrm{~g} \mathrm{KH}_{2} \mathrm{PO}_{4}$ in MilliQ water

b. Fill up to $1 \mathrm{~L}$ with MilliQ water

c. Dilute 1:20 with MilliQ water and autoclave

Store at $4{ }^{\circ} \mathrm{C}$, Shelf life: 1 year from the date of manufacture

4. MACS buffer

a. Make $500 \mathrm{ml}$ of PBS supplemented with $2 \mathrm{mM}$ EDTA and autoclave

b. Add $12.5 \mathrm{ml}$ of $0.22 \mu \mathrm{m}$-filtered 20\% BSA in PBS

Store at $4{ }^{\circ} \mathrm{C}$, Shelf life: 6 months from the date of manufacture

5. Antibody cocktail for $B$ cell isolation

$100 \mu \mathrm{l}$ of MACS buffer containing $3 \mu \mathrm{g} / \mathrm{ml}$ of biotinylated anti-CD43

$2.5 \mu \mathrm{g} / \mathrm{ml}$ of biotinylated anti-Ter119

$1.5 \mu \mathrm{g} / \mathrm{ml}$ of biotinylated anti-CD4

$1.5 \mu \mathrm{g} / \mathrm{ml}$ of biotinylated anti-CD8

$1.5 \mu \mathrm{g} / \mathrm{ml}$ of biotinylated anti-CD49b

Make the cocktail just before use

Note: Anti-CD43 antibody can be used for depletion of various immune cells except for B cells,

e.g., macrophages, granulocytes, dendritic cells, and $T$ cells. The anti-CD49b antibody recognizes NK and NKT cells. Addition of both antibodies improves the purity of $B$ cells. 
6. Antibody cocktail for feeder cell depletion (for cells from one $10 \mathrm{~cm}$ dish) $260 \mu \mathrm{l}$ of MACS buffer containing $2.89 \mu \mathrm{g} / \mathrm{ml}$ of biotinylated anti-H-2 $\mathrm{K}^{\mathrm{d}}$ To deplete plasma cells simultaneously, add biotinylated anti-CD138 at $1.15 \mu \mathrm{g} / \mathrm{ml}$ to the cocktail

Make the cocktail just before use

\section{Acknowledgments}

The present protocols are modified from the original version of our article (Nojima et al., 2011). The authors want to thank Dr. Takuya Nojima and Dr. Tatsuya Moutai for their contribution to the development of the iGB culture system. This work was supported by Grant-in-Aid for Scientific Research (B) to D.K.

\section{Competing interests}

The authors declare no conflict of interest.

\section{References}

1. Fukao, S., Haniuda, K., Nojima, T., Takai, T. and Kitamura, D. (2014). gp49B-mediated negative regulation of antibody production by memory and marginal zone B cells. $\mathrm{J}$ Immunol 193(2): 635-644.

2. Haniuda, K., Fukao, S., Kodama, T., Hasegawa, H. and Kitamura, D. (2016). Autonomous membrane IgE signaling prevents IgE-memory formation. Nat Immunol 17(9): 1109-1117.

3. Moutai, T., Yamana, H., Nojima, T. and Kitamura, D. (2014). A novel and effective cancer immunotherapy mouse model using antigen-specific B cells selected in vitro. PLoS One 9(3): e92732.

4. Nojima, T., Haniuda, K., Moutai, T., Matsudaira, M., Mizokawa, S., Shiratori, I., Azuma, T. and Kitamura, D. (2011). In-vitro derived germinal centre B cells differentially generate memory B or plasma cells in vivo. Nat Commun 2: 465.

5. Takatsuka, S., Yamada, H., Haniuda, K., Saruwatari, H., Ichihashi, M., Renauld, J. C. and Kitamura, D. (2018). IL-9 receptor signaling in memory B cells regulates humoral recall responses. Nat Immunol 19(9): 1025-1034. 